\title{
Hubungan Faktor Sosioekonomi dengan Perawakan Pendek Anak Usia 24-60 Bulan
}

Yogi Agustian, Kusnandi Rusmil, Purboyo Solek

Departemen Ilmu Kesehatan Anak RSUP Dr Hasan Sadikin / Fakultas Kedokteran Universitas Padjadjaran, Bandung

Latar belakang. Perawakan pendek merupakan salah satu indikator kesehatan anak yang dipengaruhi berbagai faktor, salah satunya sosioekonomi. Faktor sosioekonomi di antaranya pendidikan, pekerjaan, penghasilan, jumlah anak kurang dari 5 tahun, dan interval usia dengan anak sebelumnya.

Tujuan. Mengetahui hubungan status sosioekonomi dengan perawakan pendek.

Metode. Studi potong lintang dilakukan pada anak usia 24-60 bulan yang datang ke Puskesmas Sukajadi dan Tempat Penitipan Anak Bunda Ganesa pada bulan Mei 2018. Sampel dipilih secara proporsional random sampling. Tinggi badan anak diperiksa dan diambil data status sosioekonomi. Analisis statistik menggunakan Chi kuadrat dan analisis multivariat dengan regresi logistik.

Hasil. Seratus tiga puluh tiga anak terdiri dari 77 anak dari Puskesmas Sukajadi dan 56 anak dari Bunda Ganesa. Prevalensi perawakan pendek di Puskesmas Sukajadi 40,3\%, sedangkan di Bunda Ganesa 16,1\%. Tempat penelitian, pendidikan orang tua, berat badan menurut usia, pekerjaan ayah dan pendapatan keluarga memiliki hubungan bermakna dengan perawakan pendek. Analisis multivariat ayah pendidikan menengah dan rendah, serta berat badan menurut usia yang abnormal merupakan risiko perawakan pendek. Sementara anak yang tidak mendapat ASI eksklusif berisiko lebih rendah.

Kesimpulan. Prevalensi perawakan pendek lebih besar pada anak dari keluarga sosioekonomi menengah kebawah. Pendidikan ayah dan ibu, berat badan menurut usia, pekerjaan ayah dan pendapatan keluarga memiliki hubungan yang bermakna terhadap perawakan pendek. Sari Pediatri 2018;20(2):106-14

Kata kunci: perawakan pendek, sosioekonomi

\section{Relationship of Socioeconomic Factors with Stunting Children Aged 24-60 Months}

Yogi Agustian, Kusnandi Rusmil, Purboyo Solek

Background. Stunting is one of the child's health indicator which was influenced by various factors including the socioeconomic condition of their parents. Children from lower socioeconomic level had a higher risk of short stature. Socioeconomic factors consist of education, occupation, income, number of children aged less than 5 years, number of family members and age interval with the previous child.

Objective. To know the association between socioeconomic status and incidence of stunting

Methods. This cross-sectional study was participated by children aged $24-60$ months who visited Puskesmas Sukajadi and Bunda Ganesa Daycare Center during May 2018. The sample was chosen proportionally by randomly sampling. Body height was measured and socioeconomic data was taken. Statistical analysis was done using Chi-square. P value $<0,05$ was considered statistically significant. We also did a multivariate analysis with logistic regression.

Results. One hundred thirty-three children met study criteria which consist of 77 children from Puskesmas Sukajadi and 56 children from Bunda Ganesa. Stunting prevalence from Puskesmas Sukajadi was 40,3\%, while Bunda Ganesa was 16,1\%. Study setting, parent's education, weight by age, father's occupation, and family income had a significant association with stunting $(\mathrm{p}<0,05)$. Multivariate analysis of middle father education (OR 2,243 (0,980-5,085)), low (4,164 (1,597-10,860)), and abnormal weight by age (OR 6,649 $(1,674-26,407))$. Children who are not exclusively breastfed have a lower risk (OR $0.462(0.210-1.014))$.

Conclusion. Stunting prevalence is higher in children of lower socioeconomic status. Parent's education, weight by age, father's occupation, and family income has a significant association with short stature Sari Pediatri 2018;20(2):106-14

Keywords: stunting, socioeconomic

Alamat korespondensi: Yogi Agustian. Departemen Ilmu Kesehatan Anak, RSUP Dr Hasan Sadikin / Fakultas Kedokteran Universitas Padjadjaran Bandung. Jalan Pasteur no. 38 Bandung, Jawa Barat. dryogiagustian@gmail.com/. 
Yogi Agustian dkk: Hubungan faktor sosioekonomi dengan perawakan pendek anak usia 24-60 bulan

$\mathrm{P}$ erawakan pendek mencerminkan kegagalan dalam menerima nutrisi yang cukup dalam jangka waktu lama. ${ }^{1}$ Anak dengan tinggi badan berdasarkan usia $(\mathrm{TB} / \mathrm{U})<-2$ Standar Deviasi (SD) menurut World Health Organization Chart Growth Standard dikatakan perawakan pendek. ${ }^{2}$ Perawakan pendek merupakan salah satu masalah kesehatan di seluruh dunia dan mengenai 178 juta anak di bawah 60. ${ }^{3}$ World Health Organization (WHO) memiliki target menurunkan $40 \%$ anak perawakan pendek usia kurang dari 60 bulan pada tahun 2025. ${ }^{4}$ Perhatian internasional terhadap perawakan pendek meningkat berdasarkan tingginya angka perawakan pendek secara global, konsekuensi jangka pendek dan jangka panjang perawakan pendek, adanya kesepakatan internasional tentang definisi dan standar pertumbuhan manusia normal yang berlaku secara global dan perawakan pendek merupakan permasalahan lintas sektoral yang menuntut pemecahan masalah multisektor. ${ }^{5,6}$

Perawakan pendek memiliki berbagai dampak terhadap anak, baik jangka pendek maupun panjang. Perawakan pendek berhubungan dengan perhatian yang kurang, gangguan daya ingat, gangguan proses belajar, pendaftaran sekolah yang kurang, penurunan fungsi kognitif yang lebih tinggi dan perkembangan kognitif yang lambat yang pada akhirnya akan berdampak terhadap rendahnya produktivitas dan penghasilan pada saat dewasa. ${ }^{7,8}$

Perawakan pendek paling banyak mengenai anak kurang dari 60 bulan karena kebutuhan nutrisi yang tinggi tidak diikuti pemenuhan nutrisi yang adekuat. ${ }^{8}$ Penyebab perawakan pendek multifaktor dan saling berhubungan. Faktor yang secara langsung adalah asupan nutrisi yang buruk dan infeksi, sedangkan faktor yang mendasarinya, antara lain, sosioekonomi, politik, budaya, lingkungan, dan sarana prasarana kesehatan. ${ }^{9} 10$ Selain itu, faktor endokrin dan genetik juga memengaruhi perawakan pendek walaupun hanya sekitar 5\%. ${ }^{11}$ Faktor sosioekonomi orang tua berpengaruh terhadap perawakan pendek. Pendidikan, pendapatan, pekerjaan, jumlah anak kurang dari 60 bulan dan jarak kelahiran dengan anak sebelumnya merupakan faktor sosioekonomi yang dapat berpengaruh terhadap perawakan pendek. ${ }^{8,12,13}$

Perawakan pendek erat kaitannya dengan kemiskinan (sosioekonomi rendah). Prevalensi perawakan pendek lebih rendah pada anak yang berasal dari keluarga dengan pendapatan per kapita yang lebih tinggi. Anak yang tinggal pada daerah dengan pendapatan yang rendah lebih tinggi untuk terkena penyakit sehingga meningkatkan risiko untuk terjadi perawakan pendek. Perawakan pendek juga lebih banyak ditemukan pada anak dengan tingkat pendidikan ibu yang rendah dan tinggal dirumah dengan penghuni yang banyak. ${ }^{8}$

Pengetahuan mengenai prevalensi dan faktor yang berhubungan dengan perawakan pendek penting untuk mengembangkan strategi intervensi menurunkan prevalensi perawakan pendek. Di Bandung belum ada penelitian pengaruh faktor sosioekonomi terhadap perawakan pendek anak usia 24-60 bulan. Penelitian ini bertujuan mengetahui hubungan faktor sosioekonomi dengan perawakan pendek pada anak usia 24-60 bulan.

\section{Metode}

Penelitian analitik korelatif dengan rancangan potong lintang dilakukan pada anak yang berkunjung ke klinik Kesehatan Ibu dan Anak (KIA), Manajemen Terpadu Balita Sakit (MTBS) dan Posyandu wilayah kerja Puskesmas Sukajadi dan Tempat Penitipan Anak (TPA) Bunda Ganesa, Bandung. Data diambil pada bulan Mei 2018. Kriteria inklusi anak usia 24-60 bulan, sehat fisik, dan bersedia menjadi subyek penelitian. Kriteria eksklusi adalah anak yang memiliki penyakit kronis, gangguan susunan saraf pusat atau cacat bawaan.

Subjek penelitian diambil secara proporsional random sampling sesuai subjek minimum terpenuhi. Subjek dilakukan pengukuran tinggi dan berat badan kemudian orang tua diminta mengisi kuesioner untuk mendapatkan data antara lain usia, jenis kelamin, tinggi badan, tingkat pendidikan orang tua, pendapatan orang tua yang diklasifikasikan sesuai dengan World Bank, ${ }^{14}$ pekerjaan orang tua yang diklasifikasikan sesuai survey angkatan kerja nasional 2012, jumlah anak kurang dari 60 bulan dalam keluarga, jarak kelahiran dengan anak sebelumnya dan urutan kelahiran.

Analisis statistik uji Chi kuadrat untuk mengetahui hubungan berbagai faktor risiko terhadap perawakan pendek. Analisis multivariat untuk memprediksikan faktor yang berhubungan dengan perawakan pendek dengan regresi logistik. Analisis data dilakukan menggunakan statistical product and service solution (SPSS) for windows 21.0. Penelitian ini telah mendapat persetujuan Komite Etik Penelitian Kesehatan Universitas Padjadjaran. 


\section{Hasil}

Pada penelitian didapatkan 133 anak yang masuk dalam penelitian yang terdiri dari 77 anak berasal dari Puskesmas Sukajadi dan 56 anak berasal dari TPA Bunda Ganesa. Tabel 1 menunjukkan bahwa sebagian besar subjek usia ibu 20-35 tahun, pendidikan orang tua menengah dan tinggi, penghasilan keluarga Rp. 1.250.000-5.000.000, interval kelahiran $>24$ bulan, urutan_kelahiran 1-2, jumlah anggota keluarga 2-4 orang, dan anak mendapat ASI eksklusif. Di Puskesmas Sukajadi, pendidikan ayah dan ibu paling banyak adalah sekolah menengah dan sekolah dasar, pekerjaan ayah paling banyak adalah sebagai pekerja kasar dan dagang, pekerjaan ibu paling banyak adalah ibu rumah tangga, penghasilan keluarga Rp. 1.250.0005.000.000. Di Bunda Ganesa pendidikan ayah dan ibu paling banyak adalah sekolah tinggi, pekerjaan ayah dan ibu paling banyak adalah sebagai tenaga profesional ataupun manajer, dan penghasilan keluarga di atas Rp. 5.000.000.

Tabel 2 menunjukkan prevalensi perawakan pendek di Puskesmas Sukajadi adalah 40,3\%, sedangkan di Bunda Ganesa 16,1\% dengan prevalensi keseluruhan 30,0\%. Berdasarkan Tabel 2, tempat penelitian, pendidikan ayah dan ibu, pekerjaan ayah, pendapatan keluarga berbeda dan berat badan menurut usia bermakna secara statistik $(\mathrm{p}<0,05)$. Berdasarkan jenis kelamin, usia orang tua, interval kelahiran, urutan kelahiran, jumlah anak kurang dari 60 bulan, jumlah anggota keluarga tidak menunjukkan perbedaan yang bermakna $(\mathrm{p}>0,05)$.

Tabel 3. menunjukkan analisis multivariat dengan regresi logistik untuk mengetahui faktor yang paling berpengaruh pada perawakan pendek. Dari analisis multivariat menunjukkan bahwa faktor yang paling berpengaruh pada perawakan pendek di antaranya pendidikan ayah menengah dan rendah, serta berat

Tabel 1. Karakteristik subjek penelitian

\begin{tabular}{|c|c|c|c|}
\hline \multirow[t]{2}{*}{ Variabel } & \multicolumn{2}{|c|}{ Lokasi penelitian } & \multirow{2}{*}{$\begin{array}{l}\text { Jumlah } \\
(\mathrm{n}=133)\end{array}$} \\
\hline & $\begin{array}{c}\text { Puskesmas } \\
\text { Sukajadi }(\mathrm{n}=77)\end{array}$ & $\begin{array}{c}\text { Bunda Ganesa } \\
(\mathrm{n}=56)\end{array}$ & \\
\hline \multicolumn{4}{|l|}{ Jenis kelamin } \\
\hline Laki-laki & 36 & 32 & 68 \\
\hline Perempuan & 41 & 24 & 65 \\
\hline \multicolumn{4}{|c|}{ Usia ibu (tahun) } \\
\hline$<20$ & 1 & 0 & 1 \\
\hline $20-35$ & 59 & 35 & 94 \\
\hline$\geq 35$ & 17 & 21 & 38 \\
\hline \multicolumn{4}{|c|}{ Usia ayah (tahun) } \\
\hline $20-35$ & 39 & 23 & 62 \\
\hline$>35$ & 38 & 33 & 71 \\
\hline \multicolumn{4}{|c|}{ Pendidikan ayah } \\
\hline Dasar & 22 & 0 & 22 \\
\hline Menengah & 48 & 3 & 84 \\
\hline Tinggi & 9 & 53 & 79 \\
\hline \multicolumn{4}{|c|}{ Pendidikan ibu } \\
\hline Dasar & 25 & 0 & 25 \\
\hline Menengah & 46 & 2 & 48 \\
\hline Tinggi & 6 & 54 & 60 \\
\hline \multicolumn{4}{|l|}{$\mathrm{BB} / \mathrm{U}$} \\
\hline$<-3 S D$ & 2 & 0 & 2 \\
\hline$<-2 S D$ & 8 & 0 & 8 \\
\hline Normal & 66 & 54 & 120 \\
\hline$>2 S D$ & 1 & 1 & 2 \\
\hline$>3 S D$ & 0 & 1 & 1 \\
\hline
\end{tabular}




\begin{tabular}{|c|c|c|c|}
\hline \multirow[t]{2}{*}{ Variabel } & \multicolumn{2}{|c|}{ Lokasi penelitian } & \multirow{2}{*}{$\begin{array}{l}\text { Jumlah } \\
(\mathrm{n}=133)\end{array}$} \\
\hline & $\begin{array}{c}\text { Puskesmas } \\
\text { Sukajadi }(\mathrm{n}=77)\end{array}$ & $\begin{array}{c}\text { Bunda Ganesa } \\
(\mathrm{n}=56)\end{array}$ & \\
\hline \multicolumn{4}{|l|}{$\mathrm{BB} / \mathrm{TB}$} \\
\hline$<-2 S D$ & 2 & 1 & 3 \\
\hline Normal & 72 & 53 & 125 \\
\hline$>2 \mathrm{SD}$ & 2 & 1 & 3 \\
\hline$>3 \mathrm{SD}$ & 1 & 1 & 2 \\
\hline \multicolumn{4}{|l|}{ Pekerjaan ayah } \\
\hline Profesional, manager, teknisi & 9 & 49 & 58 \\
\hline Tenaga tata usaha & 2 & 0 & 2 \\
\hline Usaha jasa/dagang & 27 & 5 & 32 \\
\hline Pekerja terampil & 0 & 2 & 2 \\
\hline Pekerja kasar/buruh & 39 & 0 & 39 \\
\hline \multicolumn{4}{|l|}{ Pekerjaan ibu } \\
\hline Profesional,manager,teknisi & 1 & 35 & 36 \\
\hline Tenaga tata usaha & 1 & 4 & 5 \\
\hline Usaha jasa/dagang & 10 & 5 & 15 \\
\hline Pekerja terampil & 1 & 0 & 1 \\
\hline Pekerja kasar/buruh & 5 & 0 & 5 \\
\hline Tidak bekerja/IRT & 59 & 12 & 71 \\
\hline \multicolumn{4}{|l|}{ Pendapatan keluarga } \\
\hline$<1,25$ juta & 5 & 0 & 5 \\
\hline $1,25-5$ juta & 69 & 9 & 78 \\
\hline $5-15$ juta & 3 & 28 & 31 \\
\hline$>15$ juta & 0 & 19 & 19 \\
\hline \multicolumn{4}{|l|}{ Interval kelahiran } \\
\hline Anak pertama & 25 & 33 & 58 \\
\hline $0-23$ bulan & 3 & 2 & 5 \\
\hline$\geq 24$ bulan & 49 & 21 & 70 \\
\hline \multicolumn{4}{|l|}{ Jumlah anak $<5$ tahun } \\
\hline Satu & 58 & 33 & 91 \\
\hline Dua & 19 & 23 & 42 \\
\hline \multicolumn{4}{|l|}{ Jumlah anggota keluarga } \\
\hline $2-4$ & 28 & 43 & 71 \\
\hline $5-7$ & 33 & 13 & 46 \\
\hline$>7$ & 16 & 0 & 16 \\
\hline \multicolumn{4}{|l|}{ Urutan kelahiran : } \\
\hline $1-2$ & 60 & 48 & 108 \\
\hline 3 atau lebih & 17 & 8 & 25 \\
\hline \multicolumn{4}{|l|}{ ASI eksklusif } \\
\hline Ya & 57 & 40 & 97 \\
\hline Tidak & 20 & 116 & 36 \\
\hline
\end{tabular}


Tabel 2. Hubungan berbagai faktor risiko dengan perawakan pendek

\begin{tabular}{|c|c|c|c|}
\hline $\begin{array}{l}\text { Variabel } \\
(\mathrm{n}=40)\end{array}$ & $\begin{array}{c}\mathrm{Ya} \\
(\mathrm{n}=93)\end{array}$ & Tidak & $\mathrm{p}^{*}$ \\
\hline Puskesmas (\%) & & & 0,003 \\
\hline PKM Sukajadi & $31(40,3)$ & $46(59,7)$ & \\
\hline TPA Bunda Ganesa & $9(16,1)$ & $47(83,9)$ & \\
\hline Jenis kelamin (\%) & & & 0,558 \\
\hline Laki-laki & $22(32,4)$ & $46(67,6)$ & \\
\hline Perempuan & $18(27,7)$ & $47(72,3)$ & \\
\hline Usia ibu (\%,tahun) & & & 0,124 \\
\hline$<20$ & $1(100)$ & 0 & \\
\hline $20-35$ & $31(33,0)$ & $63(67,0)$ & \\
\hline$\geq 35$ & $8(21,1)$ & $30(78,9)$ & \\
\hline Usia ayah (\%, tahun) & & & 0,608 \\
\hline $20-35$ & $20(32,3)$ & $42(67,7)$ & \\
\hline$>35$ & $20(28,2)$ & $51(71,8)$ & \\
\hline Pendidikan ayah (\%) & & & 0,003 \\
\hline Dasar & $11(50,0)$ & $11(50,0)$ & \\
\hline Menengah & $19(38,8)$ & $30(61,2)$ & \\
\hline Tinggi & $10(16,1)$ & $52(83,9)$ & \\
\hline Pendidikan ibu (\%) & & & 0,009 \\
\hline Dasar & $11(44,0)$ & $14(56,0)$ & \\
\hline Menengah & $19(39,6)$ & $29(60,4)$ & \\
\hline Tinggi & $10(16,7)$ & $50(83,3)$ & \\
\hline $\mathrm{BB} / \mathrm{U}(\%)$ & & & 0,006 \\
\hline$<-3 S D$ & $2(100)$ & 0 & \\
\hline$<-2 S D$ & $6(75)$ & $2(25,0)$ & \\
\hline Normal & $32(26,7)$ & $88(73,3)$ & \\
\hline$>2 \mathrm{SD}$ & 0 & $2(100)$ & \\
\hline$>3 \mathrm{SD}$ & 0 & $1(100)$ & \\
\hline BB/TB (\%) & & & 0,524 \\
\hline$<-2 S D$ & 0 & $3(100,0)$ & \\
\hline Normal & $39(31,2)$ & $86(68,8)$ & \\
\hline$>2 \mathrm{SD}$ & $1(33,3)$ & $2(66,7)$ & \\
\hline$>3 \mathrm{SD}$ & 0 & $2(100)$ & \\
\hline Pekerjaan ayah (\%) & & & 0,040 \\
\hline Profesional, manager, teknisi & $10(17,2)$ & $48(82,8)$ & \\
\hline Tenaga tata usaha & 0 & $2(100)$ & \\
\hline Usaha jasa/dagang & $12(37,5)$ & $20(62,5)$ & \\
\hline Pekerja terampil & $1(50,0)$ & $1(50,0)$ & \\
\hline Pekerja kasar/buruh & $17(43,6)$ & $22(56,4)$ & \\
\hline Pekerjaan ibu (\%) & & & 0,277 \\
\hline Profesional, manager, teknisi & $8(22,2)$ & $28(77,8)$ & \\
\hline Tenaga tata usaha & 0 & $5(100)$ & \\
\hline Usaha jasa/dagang & $5(33,3)$ & $10(66,7)$ & \\
\hline Pekerja terampil & 0 & $1(100)$ & \\
\hline Pekerja kasar/buruh & $3(60,0)$ & $2(40,0)$ & \\
\hline Tidak bekerja/IRT & $24(33,8)$ & $47(66,2)$ & \\
\hline
\end{tabular}


Yogi Agustian dkk: Hubungan faktor sosioekonomi dengan perawakan pendek anak usia 24-60 bulan

\begin{tabular}{|c|c|c|c|}
\hline $\begin{array}{l}\text { Variabel } \\
(\mathrm{n}=40)\end{array}$ & $\begin{array}{c}\mathrm{Ya} \\
(\mathrm{n}=93)\end{array}$ & Tidak & $\mathrm{p}^{*}$ \\
\hline Pendapatan keluarga (\%) & & & 0,012 \\
\hline$<1,25$ juta & $1(20)$ & $4(80)$ & \\
\hline $1,25-5$ juta & $32(41,0)$ & $46(59,0)$ & \\
\hline 5-15 juta & $5(16,1)$ & $26(83,9)$ & \\
\hline$>15$ juta & $2(10,5)$ & $17(89,5)$ & \\
\hline Interval kelahiran (\%) & & & 0,407 \\
\hline Anak pertama & $14(24,1)$ & $44(75,9)$ & \\
\hline $0-23$ bulan & $2(40,0)$ & $3(60,0)$ & \\
\hline$\geq 24$ bulan & $24(34,3)$ & $46(65,7)$ & \\
\hline Jumlah anak $<5$ tahun (\%) & & & 0,578 \\
\hline Satu & $26(28,6)$ & $65(71,4)$ & \\
\hline Dua & $14(33,3)$ & $28(66,7)$ & \\
\hline Jumlah anggota keluarga(\%) & & & 0,445 \\
\hline $2-4$ & $20(28,2)$ & $51(71,8)$ & \\
\hline $5-7$ & $13(28,3)$ & $33(71,7)$ & \\
\hline$>7$ & $7(43,8)$ & $9(56,3)$ & \\
\hline Urutan kelahiran (\%) & & & 0,230 \\
\hline $1-2$ & $30(27,8)$ & $78(72,2)$ & \\
\hline 3 atau lebih & $10(40,0)$ & $15(60,0)$ & \\
\hline ASI eksklusif & & & 0,103 \\
\hline Ya & $33(34,0)$ & $64(66,0)$ & \\
\hline Tidak & $7(19,4)$ & $29(80,6)$ & \\
\hline
\end{tabular}

Keterangan : *) uji Chi-kuadrat; bermakna jika $\mathrm{p}<0,05$

Tabel 3. Analisis regresi logistik ganda

\begin{tabular}{lcccc}
\hline Variabel & Koef (B) & SE (B) & Nilai p & OR (IK95\%) \\
\hline Model awal & & & & \\
$\quad$ Lokasi penelitian & $-0,048$ & 0,691 & 0,944 & $0,953(0,246-3,690)$ \\
Usia ibu & $-0,431$ & 0,505 & 0,394 & $0,650(0,242-1,749)$ \\
Pendidikan ayah & 0,668 & 0,426 & 0,117 & $1,951(0,846-4,500)$ \\
Pendidikan ibu & $-0,245$ & 0,404 & 0,543 & $0,782(0,355-1,726)$ \\
BB/U & 1,898 & 0,723 & 0,009 & $6,675(1,617-27,552)$ \\
Pekerjaan ayah & 0,203 & 0,164 & 0,215 & $1,225(0,889-1,689)$ \\
Pendapatan keluarga & $-0,117$ & 0,420 & 0,780 & $0,889(0,390-2,027)$ \\
Urutan kelahiran & $-0,040$ & 0,488 & 0,935 & $0,961(0,369-2,502)$ \\
ASI eksklusif & $-0,862$ & 0,413 & 0,037 & $0,422(0,188-0,949)$ \\
Model akhir & & & & \\
$\quad$ Pendidikan ayah & & & & \\
Menengah & 0,808 & 0,418 & 0,053 & $2,243(0,980-5,085)$ \\
Rendah & 1,426 & 0,489 & 0,004 & $4,164(1,597-10,860)$ \\
BB/U (abnormal) & 1,894 & 0,704 & 0,007 & $6,649(1,674-26,407)$ \\
ASI eksklusif (tidak) & $-0,773$ & 0,401 & 0,054 & $0,462(0,210-1,014)$ \\
\hline
\end{tabular}

Keterangan : OR (IK95\%) : Odds rasio dan interval konfidensi 95\% *Referensi > Rp. 15.000.000

** Referensi Pendidikan tinggi 
Yogi Agustian dkk: Hubungan faktor sosioekonomi dengan perawakan pendek anak usia 24-60 bulan

badan menurut usia yang abnormal. Analisis regresi logistik ganda faktor yang berhubungan dengan perawakan pendek (Tabel 3).

\section{Pembahasan}

Pada penelitian ini prevalensi perawakan pendek adalah 30,7\%. Angka prevalensi anak dari Puskesmas Sukajadi lebih tinggi dibandingkan di Bunda Ganesa, yaitu 40,3\% berbanding 16,1\%. Puskesmas Sukajadi yang memiliki karakteristik sosioekonomi menengah ke bawah memiliki prevalensi perawakan pendek lebih tinggi dari anak yang berasal dari Bunda Ganesa dengan karakteristik sosioekonomi menengah ke atas. Penelitian ini sesuai dengan prevalensi di Indonesia. Data Kementerian Kesehatan Republik Indonesia pada tahun 2013 adalah 37,2\%. Jika dibandingkan dengan tahun 2010 (35,6\%) dan tahun 2007 (36,8\%) tidak menunjukkan persentase penurunan/ perbaikan yang signifikan. ${ }^{15}$ Penelitian di Etiopia Selatan pada tahun 2013 menunjukkan prevalensi perawakan pendek 52,5\%, sedangkan di Palestina prevalensi perawakan pendek 19,6\%. ${ }^{16}$ Penelitian di Mesir yang dilakukan pada tahun 2007 melaporkan bahwa prevalensi anak 24-60 bulan adalah $18,67 \% .^{12}$

Pendidikan orang tua berpengaruh terhadap kejadian perawakan pendek. Orang tua dengan tingkat pendidikan lebih tinggi memiliki risiko lebih rendah memiliki anak dengan perawakan pendek dibandingkan dengan tingkat pendidikan lebih rendah. Penelitian di Mesir pada tahun 2000 prevalensi perawakan pendek $22,56 \%$ pada ibu yang tidak sekolah dan 23,26\% pada ayah yang tidak sekolah, sedangkan prevalensi perawakan pendek sebesar $13,81 \%$ pada ibu yang lulus dari pendidikan tinggi dan $12,53 \%$ pada ayah yang lulus dari pendidikan tinggi. ${ }^{12}$ Pada penelitian ini menunjukkan hasil yang sama bahwa tingkat pendidikan ayah berhubungan, yaitu pendidikan dasar, menengah, dan tinggi secara berurutan berpengaruh pada prevalensi perawakan pendek sebesar $50 \%$, $38,8 \%$, dan $16,1 \%$. Sementara pendidikan ibu yang memiliki pendidikan dasar, menengah, dan tinggi secara berurutan berpengaruh pada prevalensi perawakan pendek sebesar secara berurutan 44,0\%, 39,6\%, dan $16,7 \%$. Orang tua dengan tingkat pendidikan lebih tinggi memiliki pengetahuan dan kemampuan untuk mengimplementasikan pengetahuannya lebih baik. Ibu yang memiliki tingkat pengetahuan lebih baik mampu merawat dan memilih jenis makanan lebih baik untuk anaknya. Hal ini disebabkan oleh kemampuan mengakses informasi mengenai nutrisi dan kesehatan.17

Pendapatan orang tua berhubungan dengan perbaikan nutrisi. Nutrisi yang baik akan menurunkan kejadian perawakan pendek. Berdasarkan penelitian yang dilakukan di Uganda menunjukkan bahwa tingkat pendapatan dan sumber pendapatan berpengaruh terhadap kejadian perawakan pendek. ${ }^{13}$ Peningkatan $10 \%$ pendapatan keluarga menurunkan prevalensi perawakan pendek sebesar 1,5\%-6\%. ${ }^{18}$ Pada penelitian ini orang tua dengan pendapatan menengah rendah, menengah atas, dan tinggi secara berturut-turut berpengaruh pada prevalensi perawakan pendek $41,0 \%, 16,1 \%$, dan $10,5 \%$. Pendapatan keluarga yang cukup akan mendukung pertumbuhan anak karena orang tua dapat memenuhi kebutuhan nutrisi anak. ${ }^{17}$

Pekerjaan orang tua berpengaruh terhadap kejadian perawakan pendek. Ibu yang bekerja memiliki risiko lebih besar anak ber perawakan pendek. Ibu yang bekerja berakibat berkurangnya waktu kontak dengan anak, pendeknya waktu ASI eksklusif dan pemberian ASI, meningkatnya pemberian makanan tambahan yang tidak benar yang berakibat negatif terhadap pertumbuhan anak. ${ }^{8}$ Pada penelitian ini, prevalensi perawakan pendek pekerjaan ayah yang profesional lebih rendah $(17,2 \%)$ dibandingkan buruh $(43,6 \%)$. Sementara ibu yang bekerja profesional memiliki prevalensi perawakan pendek $22,2 \%$ dibandingkan buruh $60,0 \%$ dan ibu rumah tangga 33,8\%. Namun, secara statistik tidak bermakna sesuai dengan penelitian di Mesir yang memiliki prevalensi $17,76 \%$ pada ibu yang bekerja. ${ }^{12}$ Pada penelitian ini, ibu yang bekerja tidak berpengaruh terhadap perawakan pendek anak. Hal ini dapat disebabkan karena ibu yang bekerja memberikan pendapatan keluarga sehingga kebutuhan anak dapat terpenuhi. ${ }^{17}$

Jumlah anak kurang dari 5 tahun dalam keluarga berhubungan dengan kejadian perawakan pendek. Keluarga yang memiliki anak di bawah 60 bulan lebih dari satu memiliki prevalensi perawakan pendek yang lebih besar. ${ }^{8}$ Penelitian ini menunjukkan bahwa keluarga yang memiliki anak usia kurang dari 5 tahun lebih dari 1 memiliki prevalensi terhadap perawakan pendek lebih besar dibandingkan dengan keluarga yang memiliki 1 anak di bawah 5 tahun. Penelitian di Etiopia menunjukkan bahwa keluarga yang memiliki anak di bawah 60 bulan lebih dari 1 memiliki prevalensi 
Yogi Agustian dkk: Hubungan faktor sosioekonomi dengan perawakan pendek anak usia 24-60 bulan

perawakan pendek sebesar $48,9 \%$ dibandingkan yang memiliki 1 anak $<60$ bulan $34,2 \% .{ }^{8} \mathrm{Hal}$ ini dapat disebabkan keluarga yang memiliki anak kurang dari 5 tahun lebih dari 1 membutuhkan biaya yang lebih besar dan ibu dengan 2 anak atau lebih di bawah 5 tahun akan mengalami kesulitan dalam mengurus anak dan tidak dapat bekerja untuk membantu pendapatan keluarga.

Interval kelahiran dengan anak sebelumnya berpengaruh terhadap kejadian perawakan pendek. Interval kelahiran $<24$ bulan memiliki prevalensi perawakan pendek lebih besar dibandingkan dengan interval kelahiran $>24$ bulan. ${ }^{8}$ Penelitian di Mesir tahun 2000 melaporkan prevalensi perawakan pendek anak dengan interval kelahiran $<24$ bulan dari anak sebelumnya memiliki angka lebih besar $(23,4 \%)$ dibanding dengan interval kelahiran $>24$ bulan $(19,83 \%){ }^{12}$ Pada penelitian ini menunjukkan hasil interval kelahiran $<24$ bulan memiliki prevalensi perawakan pendek $40,0 \%$, sedangkan interval kelahiran $>24$ bulan 34,3\%. Penelitian ini sesuai dengan penelitian sebelumnya di Kongo yang melaporkan prevalensi perawakan pendek pada interval kelahiran $<24$ bulan $43,5 \%$ dan $>24$ bulan sebesar $44,5 \% .{ }^{19}$ Interval kelahiran kurang dari 24 bulan memiliki risiko untuk melahirkan anak dengan berat badan lahir rendah. Bayi berat lahir rendah merupaka risiko untuk terjadinya perawakan pendek. ${ }^{20}$

Penelitian ini menunjukkan anak yang mendapat ASI eksklusif memiliki risiko lebih besar dibandingkan dengan anak yang tidak mendapat ASI eksklusif. Penelitian ini berbeda dengan penelitian di Etiopia yang melaporkan bahwa anak yang tidak mendapatkan ASI eksklusif selama 6 bulan memiliki risiko 1,9 kali lipat dibandingkan anak yang mendapat ASI eksklusif selama 6 bulan. Hal ini disebabkan masih ada anak yang mendapat ASI eksklusif 8-9 bulan. Menurut WHO, ${ }^{21}$ ASI eksklusif yang diberikan lebih dari 6 bulan tidak dapat memenuhi kebutuhan anak sehingga menyebabkan gagal tumbuh. Selain itu, anak yang mendapat ASI eksklusif sering kesulitan dalam memulai mendapat makanan pendamping, sedangkan kuantitas ASI sudah berkurang sehingga tidak dapat memenuhi kebutuhan nutrisi. Selain itu, banyak orang tua yang tidak mengetahui jenis makanan yang diberikan untuk memulai pemberian makanan pendamping. ${ }^{22,23}$

Keterbatasan penelitian ini adalah tidak menggali asupan nutrisi dan tidak mengukur tinggi badan orang tua. Saran penelitian selanjutnya menggali asupan nutrisi dan mengukur tinggi badan.

\section{Kesimpulan}

Penyebab perawakan pendek multifaktor di antaranya status sosioekonomi keluraga. Pendapatan, pekerjaan, dan pendidikan orang tua serta pemberian ASI eksklusif berpengaruh terhadap prevalensi perawakan pendek.

\section{Daftar pustaka}

1. Dewana Z, Fikadu T, Facha W, Mekonnen N. Prevalence and predictors of stunting among children of age between 24 to 59 months in Butajira Town and Surrounding District, Gurage Zone, Southern Ethiopia. Health Scie J 2017;11:1-6.

2. WHO. Country profile indicators : interpretation guide. Geneva: WHO; 2010.

3. Souganidis E. The relevance of micronutrients to the prevention of stunting. Sight Life Mag 2012;26:10-8.

4. WHO. Resolution WHA65.6. Maternal, infant and young child nutrition. Geneva: WHA65/2012/REC/1. May 21-262012. Geneva: WHO; 2012.

5. Onis M, Dewey KG, Borghi E, Onyango AW, Blössner M, Daelmans B, dkk. The World Health Organization's global target for reducing childhood stunting by 2025: rationale and proposed actions. Mater Child Nutr 2013;9:6-26.

6. Onis M, Branca F. Childhood stunting: a global perspective. Mater Child Nutr 2016;12:12-26.

7. Tarigan R, Dhamayanti M, Fadlyana E, Rusmil K. Different result of cognitive impairment screening in adolescent aged 10-12 years with normal and short stature in Pangandaran District. Am J Clin Med Res 2017;5:26-30.

8. Fikadu T, Assegid S, Dube L. Factors associated with stunting among children of age 24 to 59 months in Meskan district, Gurage Zone, South Ethiopia: a case-control study. BMC Pub Health 2014;14:800.

9. Stewart CP, Iannotti L, Dewey KG, Michaelsen KF, Onyango AW. Contextualising complementary feeding in a broader framework for stunting prevention. Matern Child Nutr 2013;9:27-45.

10. Sahitarani AS, Paramashanti BA, Sulistyawati. Relationship between stunting with frequency and duration of infection disease in children age 24-59 months. Indonesian J Nutr Dietetics 2017;5:47-53.

11. Soetjiningsih. Perawakan pendek. Dalam: Soetjiningsih, 
Ranuh ING, penyunting. Tumbuh kembang anak. Jakarta: EGC; 2013.161-24.

12. Zottarelli LK, Sunil TS, Rajaram S. Influence of parental and socioeconomic factors on stunting in children under 5 years in Egypt. Rev Med Orie 2007;13:1476-85.

13. Kirk A, Kilic T, Carletto C. Composition of household income and child Nutrition outcomes evidence from Uganda. World Dev 2018;109:452-69.

14. Gross national income per capita 2016, Atlas method and PPP [database on the internet]2017. Diakses pada 20 Juli 2018. Didapat dari: http://data.worldbank.org/data-catalog/ world-development-indicators.

15. Situasi perawakan pendek. Dalam: RI KK, penyunting. Jakarta: Pusat data dan informasi; 2016.

16. Kishawi RRE, Soo KL, Abed YA, Muda WAMW. Prevalence and associated factors influencing stunting in children aged 2-5 years in the Gaza Strip-Palestine: a cross-sectional study. BMC Pediatrics 2017;17:210.

17. Handayani F, Siagian A, Aritonang EY. Mother's education as a determinant of stunting among children of age 24 to 59 months in North Sumatera Province of Indonesia. IOSR-JHSS
2017;22:58-64.

18. McGovern ME, Krishna A, Aguayo VM, Subramanian S. A review of the evidence linking child stunting to economic outcomes. Int J Epidemiol 2017;46:1171-91.

19. Kandala N-B, Madungu TP, Emina JB, Nzita KP, Cappuccio FP. Malnutrition among children under the age of five in the Democratic Republic of Congo (DRC): does geographic location matter? BMC Pub Health 2011;11:261.

20. Sobrino M, Gutierrez C, Alarcon J, Davila M, Cunha A. Birth interval and stunting in children under five years of age in Peru (1996-2014). Child Care Health Dev 2017;43:97-103.

21. WHO. Infant and young child feeding. Diakses pada 20 Juli 2018. Didapat dari: http://www.who.int/news-room/fact-sheets/ detail/infant-and-young-child-feeding.

22. Cruz LMG, Azpeitia GG, Súarez DR, Rodríguez AS, Ferrer JFL, Serra-Majem L. Factors associated with stunting among children aged 0 to 59 months from the Central Region of Mozambique. Nutrients 2017;9:491.

23. Candra A, Puruhita N, Susanto J. Risk Factors of Stunting among 1-2 Years Old Children in Semarang City. M Med Indones 2011;45:206-12. 